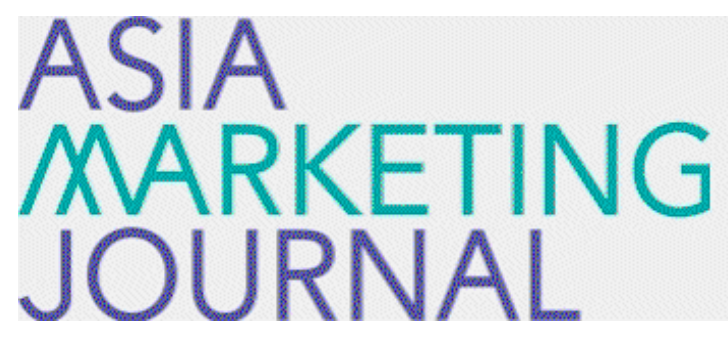

ASIA MARKETING JOURNAL

Volume 15 | Issue 2

Article 3

7-30-2013

\title{
The Effect of P-O Fit on the Frontline Employee`s Boundary Spanning Behaviors
}

Jae Won Yoo

Follow this and additional works at: https://amj.kma.re.kr/journal

Part of the Marketing Commons

\section{Recommended Citation}

Yoo, Jae Won (2013) "The Effect of P-O Fit on the Frontline Employee`s Boundary Spanning Behaviors," Asia Marketing Journal: Vol. 15 : Iss. 2 , Article 3.

Available at: https://doi.org/10.53728/2765-6500.1518

This Article is brought to you for free and open access by Asia Marketing Journal. It has been accepted for inclusion in Asia Marketing Journal by an authorized editor of Asia Marketing Journal. 


\section{The Effect of P-O Fit on the Frontline Employee's Boundary Spanning Behaviors: Mediating Role of Emotional and Motivational Responses*}

Jaewon Yoo**

In this study, the author develops and tests a model that incorporates the mediating effects of two frontline employee psychological variables (emotional exhaustion and intrinsic motivation) based on job demand and resource model. As a form of environmental resource, person-organization fit was proposed as a leading factor of frontline employee boundary spanning behavior through emotional exhaustion and intrinsic motivation.

All measures were adapted from or developed based on prior research. Data for the study were collected from a cross-sectional sample of retail bank employees in South Korea. Questionnaires were distributed to 500 frontline employees across several banks. Of these, 322 usable questionnaires were returned. To analyze the data, a structural equation model procedure using LISREL 8.5 was employed.

Results show that an employee's perceived fit with his/her organization enhances intrinsic motivation and reduces emotional exhaustion. These mechanisms, in turn, increase the employee's boundary spanning behavior. These results support the notion that person-organization fit should be one of the factors affecting motivation, affect and attachment, and extends such an understanding to a purely service-based environment among customer contact employees. Results also confirms that P-O fit can be viewed as environmental resources, and the JD-R model provides a theoretical base in further studying the antecedent role of $\mathrm{P}-\mathrm{O}$ fit on frontline employees's boundary spanning behavior through intrinsic motivation and emotional exhaustion.

These results suggest that organizations have to do their best to manage $\mathrm{P}-\mathrm{O}$ fit, be it through employee screening or training and workshops to try and align organization and employee values and objectives. If managers of organizations are positively evaluated by the employees, it will be easier for them to, give things of value to employees, such as sense of direction, values, and recognition, and receive other things in return such as esteem and responsiveness. Consequently, organizational leaders are not only able to manage employee experiences, but also their fit with the organization

\footnotetext{
* This study was supported by the Soongsil University Research Fund of 2012 ** Assistant Professor, Department of Entrepreneurialship and Small Business, School of Business, Soongsil University
(yjw1774@ssu,ac,kr)
} 
Even if a manager cannot control employee $\mathrm{P}-\mathrm{O}$ fit, this research suggests, that a focus on reducing emotional exhaustion rather than increasing intrinsic motivation seems optimal. This research also supports the idea that motivation has a direct association with a frontline employee's boundary spanning behavior. Even in situations where emotional exhaustion cannot be reduced, organizations may still influence frontline behaviors through motivation.

Key words: Boundary Spanning Behavior, Emotional Exhaustion. Intrinsic Motivation. PersonOrganization Fit, Job Demand and Resource Model

\section{Introduction}

During the past two decades, the sales management and service marketing literature have highlighted the importance of the salesperson's role within dyadic relationships, emphasizing a phenomenon labeled the, "spillover effect" (e.g., Bettencourt, Brown, and MacKenzie 2005: Park, Holloway, and Lee, 2013). Customer contact employees contribute to product and service excellence by delivering on the promises of the firm, by creating a favorable image for the firm, by going beyond the call of duty for customers and by promoting the firm's products (Bettencourt and Brown 1997). Therefore, the spillover effect between the positive attitudes and behaviors of frontline employees and a customer's evaluation of services delivered has received increased attention (Bowen, Gilliland, and Folger 1999). Further, because of the relationship of such an effect to going above and beyond one's formal role, an area of theory that has been applied most prominently in relation to the investigation of the spillover effect and an employee's behavioral outcomes has been that of organizational citizenship behavior (OCB).

OCB originated from management and organizational behavior literatures and continues to stimulate interest among researchers and practitioners. OCB is defined as behavior of the employee that is not directly or explicitly recognized by the formal reward system and which, in general, promotes the effectiveness of the organization (Podsakoff and Mackenzie 1997: Luria and Yagil 2009). Thus, OCB is widely applicable across different types of organizations and contexts (Bettencourt, Gwinner. and Meuter 2001).

Although OCB is certainly widely applicable, it has been argued that current OCB-related research is shortsighted in its investigation of the customer- and service-oriented citizenship behaviors of customer-contact employees (Podsakoff and MacKenzie 1997). Specifically, Borman and Motowidlo (1993, p. 90) argue that some 
types of OCBs, "... are probably more appropriate for certain types of organizations than others," emphasizing that the role of contact employees is unique. Based on these suggestions, Bettencourt and colleagues (2001) developed the "boundary spanning behavior" (BSB) concept to investigate pro-organization behaviors of contact employees. Empirical research has generally provided support for this distinction and has proposed the spillover effect of positive frontline employee attitudes on customer outcomes (Bettencourt et al. 2005).

Although the importance of understanding the spillover of contact employee attitudes in relation to various pro-social behaviors has been established (Bettencourt et al. 2005), few studies have been devoted to a more detailed understanding of such effects, and as researchers and practitioners we still do not have a clear picture regarding what spurs BSB among frontline employees (thereby facilitating spillover effects onto positive outcomes). Therefore, in this research, I investigate and explain the various drivers of BSB that are prominent among contact personnel.

To achieve this research goal, job demands and resource (JD-R) model is employed. The JD-R model posits that various job demands (e.g., time pressure, emotional workload, problems in physical work environment) may lead to resource loss, such as health problems and reduction of employee energy resources in the form of burnout. On the other hand, the JD-R model also suggests that job resources (e.g., autonomy, immediate feedback, and rewards) are especially salient for resource gain such as true well-being and motivation at work. Thus, regarding resource losses and gains, the JD-R model can be viewed as the more general and parsimonious model for a stressful boundary spanners' work-related application.

As such, consistent with JD-R model, the extent of an employee's fit with their organization ( $\mathrm{P}-\mathrm{O}$ fit) has been studied as a potential driver of work attitude (Cable and Judge 1996) and/or behavioral outcomes (O’Reilly et al. 1991). Further, both emotional exhaustion and intrinsic motivation have been found as a consequence of P-O fit (Zoghbi et al. 2007). Based upon this, I suggest $\mathrm{P}-\mathrm{O}$ fit as an antecedent of contact employee BSB and investigate emotional exhaustion and intrinsic motivation as potential mediators in the relationship between $\mathrm{P}-\mathrm{O}$ fit and $\mathrm{BSB}$.

The model developed in this research is tested using a sample of frontline employees in the retail banking sector. In the next section of this paper, a background theory is presented and the research model is discussed. This is followed by a discussion of the methodology and the results of the study. The paper concludes with a discussion of theoretical and managerial implications, as well as potential avenues for future research. 


\section{Theoretical Background}

\subsection{Job Demands-Resource Model}

In an occupational context, the JD-R model has highlighted the motivational and wellnesspromoting potential of job-related resources (Bakker and Demerouti 2007: Demerouti et al. 2001). Although every occupation may have its own specific work characteristics associated with negative/positive employee outcomes such as exhaustion, burnout or motivation, one central assumption of the JD-R model is that it is still possible to model these characteristics in relation to the interplay across two broad categories (i.e., job demands and job resources) (Bakker et al. 2004). Job demands are those physical, social, or organizational aspects of the job that require sustained physical and/or psychological (i.e., cognitive or emotional) effort on the part of the employee. For example, completing highly involved projects on a tight time schedule, working toward the completion of multiple tasks simultaneously, or having the performance of multiple other employees linked to one's own performance are all indicative of potentially high job demands. Job resources are physical, psychological, social or organizational aspects of the job that (a) reduce the physiological and psychological costs associated with job demands, (b) are functional in achieving work goals, and/or (c) stimulate personal growth. learning, and development (Demerouti et al. 2001). Hence, not only are resources necessary to deal with job demands, but they also are important in their own right (Hobfoll 2002). In general, job demands and resources are negatively correlated because job demands, such as high work pressure and emotionally demanding workloads, may preclude the mobilization of job resources (Bakker et al. 2003: Demerouti et al. 2001). In a similar vein, high job resources, such as social support and feedback, may reduce job demands.

Another important assumption in the JD-R model is that work characteristics may evoke two psychologically different processes. In the first process (i.e., strain), demanding aspects of work lead to constant overtaxing and, in the long run, exhaustion (Wright and Cropanzano 1998). Exhaustion, in turn, may lead to negative consequences for the organization, such as absenteeism and impaired in-role performance (Bakker et al. 2004).

In the second process (i.e., motivational striving), job resources lead to engagement and positive outcomes (Schaufeli and Bakker 2004). For instance, Bakker et al,'s (2004) study of human service professionals showed that job resources lead to dedication and extra-role performance. This is consistent with Leithwood et al. (1999), who suggest that schools may develop commitment to the collectively held goals of the organization by providing teachers with opportunities to become increasingly com- 
petent and by developing shared decision-making possibilities (i.e., job resources).

\section{Model and Hypotheses}

The hypothesized relationships are shown in Figure 1. Specifically, the research model investigates the effect of $\mathrm{P}-\mathrm{O}$ fit, emotional exhaustion and intrinsic motivation on frontline employee BSB. In the research model, service delivery, external influence and internal influence are provided as representations of frontline employee boundary spanning behaviors. Based on past research, five sets of hypotheses are proposed for the current study.

Person-organization fit is defined as the congruence of the personality traits, beliefs, and values of individual persons with the culture, strategic needs, norms, and values of organizations (O'Reilly et al. 1991). Schneider et al.'s (1995) attraction-selection-attrition (ASA) framework also posits goal congruence as an important dimension of $\mathrm{P}-\mathrm{O}$ fit. Most of the related literature demonstrates that $\mathrm{P}-\mathrm{O}$ fit has positive benefits on a range of employee attitudes and behaviors (Bright 2007). For example, O'Reilly and Chatman (1986) found that P-O fit has a positive relationship with the number of extra-role behaviors exhibited by an employee. Posner (1992) also found that P-O fit was di-

〈Figure 1〉 Indirect Effect of P-0 fit on Boundary Spanning Behavior

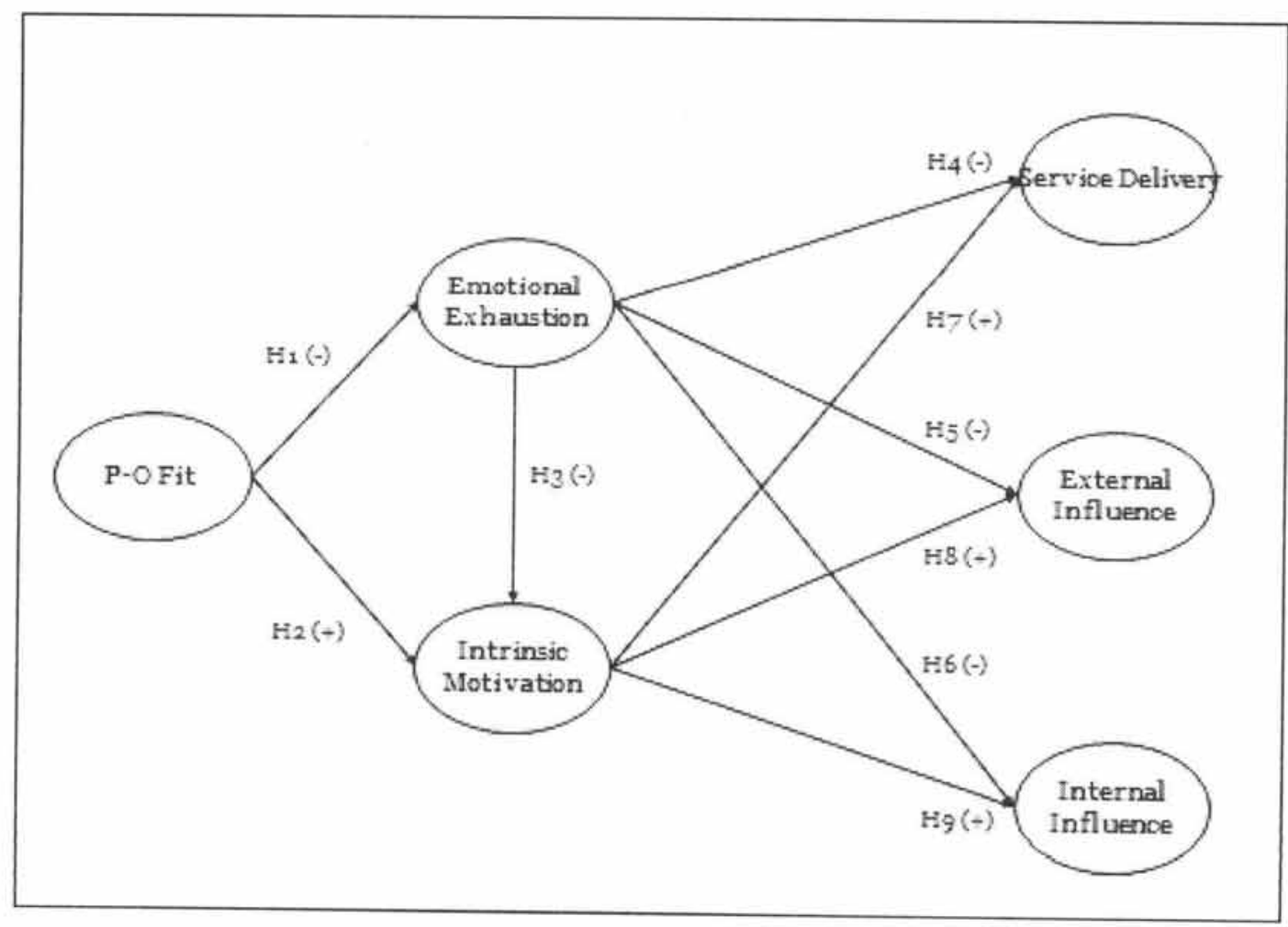


rectly related to positive work attitudes.

Emotional exhaustion is "the feeling of being emotionally overextended and exhausted by ones' work" (Maslach and Jackson 1981, p. 101). It often occurs when employees perform "peoplework" of some kind (Cordes and Dougherty 1993), where frequent interaction with persons external to the organization is a norm.

The research stream that addresses the role of emotions in service encounters involves emotional labor (e.g., Hennig-Thurau et al. 2006) and emotional exhaustion (e.g., Boles et al. 1997: Jaramillo et al. 2006). Emotional labor is the act of expressing organizationally desired emotions during service transactions (Morris and Feldman, 1996). Emotional labor is important in services because front-line employees engage in emotional work as part of their jobs, including greeting customers with a positive attitude.

According to the Maslach (1982), frequent face-to-face interactions with clients and interactions that are emotionally intense and of longer duration are associated with higher levels of emotional exhaustion. Her work also suggests that greater planning for a wide variety of emotional displays is emotionally exhausting as well. Hochschild (1983) explains that acting as part of one's work role may create emotional exhaustion for two key reasons: (1) the experience of tension from emotional dissonance and (2) the draining of resources while effortfully acting (Hochschild, 1983: Wharton, 1993). While surface acting, an individual experiences emotional dissonance owing to the discrepancy between expressions and inner feelings. Studies have found that emotional dissonance is associated with emotional exhaustion (Brotheridge and Grandey, 2002).

According to the JD-R model, both work engagement and emotional exhaustion are determined by environmental resources (Hobfoll 1989). Schaufeli and colleagues (2009) also suggest that, according to the motivational process of JD-R model, work environments offer abundant resources foster the willingness of employees to dedicated their efforts and abilities to the work task. In such environments, it is likely that the task will be completed successfully and that the work goal will be attained (Schaufeli et al. 2009). Thus P-O fit is a job related environmental resource and can be defined as positively self-evaluated environmental conditions that reinforce an employee's sense of his/her ability to successfully control and impact an environment (Hobfall 1989). Employees who experience $\mathrm{P}-\mathrm{O}$ fit will regard this perceived match as such a job resource (Schaufeli et al. 2009).

In the strain process of JD-R model, demanding aspects of work (i.e., time pressure, emotional workload, problems in physical work environment) lead to resource loss, such as health problems and reduction of employee energy resources in the form of burnout (e.g.. Wright and Cropanzano 1998). On the other hand, previous research has demonstrated that $\mathrm{P}-\mathrm{O}$ fit will be 
negatively related with perceptions of emotional exhaustion (Singh and Greenhaus 2004). According to the Singh and Greenhaus (2004). stress is reduced when an employee feels that there is a close fit between him/herself and the organization (i.e., the positive job resource helps to minimize the strain process). An employee judging a match between him/herself and the organization is likely to sense an ability to control a given context, thus minimizing the perceived potential consequences of a job stressor and minimizing perceived stress (Singh and Greenhuas 2004).

When employees perceive that their values fit well with those of the organization, they are more likely to feel self-confident and develop feelings of accomplishment (Xie and Johns 1995). Also, stress is reduced when an employee feels that there is a close fit between himherself and the organization (Singh and Greenhaus 2004). Thus, frontline employees' emotional exhaustion is likely to be partly the result of an employee's perception of misfit with organizational values. Whereas, P-O fit may elicit positive sentiments (e.g., trust, commitment and satisfaction) that, in turn, could motivate a person to perform positive actions in the organization. Thus, based on extant literature, emotional exhaustion is more likely when an employee does not possess shared values with his/her organization - a low level of $\mathrm{P}-\mathrm{O}$ fit.

\section{Hypothesis 1: Person-organization fit is neg-}

atively related to emotional exhaustion

Intrinsic motivation refers to doing an activity for the inherent satisfaction of the activity itself (Ryan and Deci 2000). Intrinsically motivated individuals appear to be better able to treat work situations that require interpreting conflicting or ambiguous demands as being challenging and stimulating, as opposed to threatening or frustrating (Keaveney and Nelson 1993). In the motivational process, job resources lead to engagement and positive outcomes (Schaufeli and Bakker 2004). As previously explained, if individuals experience high levels of accordance between the self and environment, then, they are intrinsically motivated to pursue their goals and as a result they trigger satisfaction. For instance, Bakker et al.'s (2004) study of human service professionals showed that job resources lead to dedication and extra-role performance. This is consistent with Leithwood et al. (1999), who suggest that $\mathrm{P}-\mathrm{O}$ fit may elicit positive sentiments (e.g., trust, commitment and satisfaction) that, in turn, could motivate a person to achieve their task completely in the organization. Similarly, Vroom's "expectancy theory" (1964) suggests that a person's motivation is based on the product of his or her valence (the value of an individual goal), expectancy (probability of successfully accomplishing a task), and instrumentality (probability that the successful accomplishment of the task will result in achieving a desired goal). Research related to ex- 
pectancy theory indicates that in contexts where a high level of $\mathrm{P}-\mathrm{O}$ fit exists, individuals are likely to display greater expectancy-based work motivation and job involvement, and demonstrate lower levels of turnover intention (O'Reilly et al. 1991). Thus, when employee and organizational values/goals are closer to a match, the employee is likely to exhibit higher work-related motivation. Based on this, $\mathrm{P}-\mathrm{O}$ fit may be an important prerequisite for an employee's intrinsic motivation.

Hypothesis 2: Person-organization fit is positively related to intrinsic motivation

Many studies consider emotional exhaustion as an initiator of employee burnout (Babakus et al. 1999). However, very little is known about the relationship between intrinsic motivation and burnout in the marketing literature (Karatepe and Tekinkus 2006). Since intrinsic motivation is among the key personality traits of successful frontline employees (Bettencourt and Brown 2003), it is important to understand whether emotional exhaustion diminishes a frontline employee's level of intrinsic motivation.

In relation to this, Halbesleben and Bowler (2007) explain the relationship among emotional exhaustion, motivation, and job performance in terms of the, "conservation of resources" (COR: initial stage of JD-R model) model of stress and burnout (Hobfoll 1989). According to the COR theory, people strive to obtain (or main- tain) resources that they value. When resources are lost or threatened, stress may occur. When individuals cannot deal with this stress effectively by allocating or investing new resources, prolonged stress and eventually motivation may reduce. Halbesleben and Bowler (2007) suggest that motivation serves as a mediating step, whereby those employees who are experiencing emotional exhaustion would be less motivated. Therefore, the following hypothesis is proposed.

Hypothesis 3: Emotional exhaustion is negatively related to intrinsic motivation

A growing literature has demonstrated the link between burnout and task performance (Cordes and Dougherty 1993: Wright and Bonett 1997: Wright and Cropanzano 1998). Cordes and Dougherty (1993) proposed that burnout leads to negative employee attitudes or behaviors toward customers, work, and the organization (e.g., diminished service quality, reduced degree of job involvement, or increased absenteeism, turnover, and decreased task performance). Wright and Bonett (1997) found that emotional exhaustion was related negatively to task performance. Moreover, on the basis of conservation of resources theory, Wright and Cropanzano (1997) demonstrated that emotional exhaustion had a significant negative effect on task performance after controlling for the effects of positive and negative affectivity.

According to the social exchange theory, Social 
exchange relationships tend to involve the exchange of socio-emotional benefits. They are associated with close personal attachments and open-ended obligations. When individuals form social exchange relationships with organizations, they tend to have higher job performance, more organizational citizenship behaviors (OCB), and weaker turnover intentions (e.g., Hendrix et al. 1998: Wayne et al. 1997). Because social exchange relationships emphasize the obligations, attachments, and identification that employees feel toward their employers, past research has proposed that individuals form social exchange relationships to the extent that they receive worthwhile benefits and that these benefits are assigned in a fair manner (Cropanzano et al., 2001: Cropanzano et al., 2003). Cropanzano and colleagues (2003) investigated the effects of emotional exhaustion on employees' pro-social behavior based on social exchange theory.

Based on these result, it is likely that in order to maintain emotional balance, frontline employees who experience emotional exhaustion will reduce their boundary spanning behaviors.

Hypothesis 4: Emotional exhaustion is negatively related to frontline employee service delivery.

Hypothesis 5: Emotional exhaustion is negatively related to frontline employee external representation.

Hypothesis 6: Emotional exhaustion is negatively related to frontline employee internal influence.

Oldham and Hackman (1981) argued that employees who are intrinsically motivated engage in higher levels of task performance because performing well creates positive affect. Staw (1977) made a similar argument, suggesting that intrinsically motivated individuals derive satisfaction from task accomplishment and therefore work harder to excel. Studies linking intrinsic motivation with task performance have come out of the related area of psychological empowerment (Gwinner et al. 2005). For example, Spreitzer (1995) linked the empowerment version of intrinsic motivation to subordinate perceptions of managerial task performance in an industrial firm.

Research relating intrinsic motivation to $\mathrm{OCB}$ is surprisingly rare, yet there appear to be natural links between the two constructs. Individuals likely execute discretionary behaviors that go beyond the formal requirements of a job to either satisfy some higher-order individual need or to align work behavior with individual values. Because such behaviors are less likely to be formally rewarded than are required job behaviors, they are presumably performed for self-generated, intrinsic reasons. Some support for this assertion was found by Halbesleben and Bowler (2007), who linked three types of work motivation (accomplishment, status, and communion striving motivation) to employees' pro-social behavior. 
Hypothesis 7: Intrinsic motivation is positively related to frontline employee service delivery.

Hypothesis 8: Intrinsic motivation is positively related to frontline employee external representation.

Hypothesis 9: Intrinsic motivation is positively related to frontline employee internal influence.

\section{Methodology}

\subsection{Sampling Procedure and Data Collection}

Data for the study were collected from a cross-sectional sample of retail bank employees in South Korea. The sample contained $\mathrm{re}^{-}$ sponses from both service managers and service employees. Participation was solicited from various large banks across the country. All the organizations involved in the data collection offered services and sold service products to customers directly.

The instrument was prepared in English and then translated into Korean. It was checked for accuracy in line with the conventional backtranslation processes (Brislin 1970). Data were collected on-site from each participating bank. The sample for the study was drawn with the help of chief executive officers (CEOs) who worked for 10 top ranked banks with headquarters in Seoul. In the initial contact, a cover letter was mailed explaining the purpose of the survey to the top manager and asked to persuade their branch managers to participate in the survey. Four of ten CEOs agreed to ask their branch managers to participate in the survey. Using the list of branches, suggested by CEOs, I contacted branch managers and asked to help with the survey administration.

An interviewer scheduled appointments with the branch manager as an informant, who then introduced the interviewer to the other employees in that branch. The interviewer presented the respondents with the survey questionnaire and collected the questionnaire upon completion.

\subsection{Measures}

All measures are adapted from or developed based on prior research. Individual measurement items for the constructs are listed in Appendix A. Person-organization fit was assessed using a scale developed by Netemeyer et al. (1997) that measures the congruence of personality traits, beliefs and values of an individual employee with the culture, strategic needs, norms and values of his/her organization (based on employee perceptions of this fit). Four items asked service workers to assess the fit between their personal values and the organization's values, including "I feel that my personal values 
are a good fit with my company" and "My company has the same values as I do with regard to honesty." The items are evaluated on five-point scales ranging from "strongly disagree" to "strongly agree."

To measure the emotional exhaustion component of burnout, the emotional exhaustion subscale of Maslach and Jackson (1981) was used. The emotional exhaustion subscale includes nine questions that were scored on a 7-point frequency scale ranging from "never" to "daily." Sample items include "I feel emotionally drained from my work" and "I feel frustrated by my job." Intrinsic motivation was measured with three items provided by Richard and Anderson (1994). These items were developed to measure a service employee's intrinsic goals and consideration of his/her well-being, including "When I perform well, I know it's because of my own desire to achieve."

Bettencourt et al. (2005) developed the boundary spanning behavior measures based on their conceptual definitions and prior research involving measurement of related pro-social behavior and/or service quality constructs. External representation was measured using a 4-item scale designed to tap the extent to which an employee is a vocal advocate to outsiders of his/her organization's image, goods, and services. For example, "I follow customer service guidelines with extreme care," and "I say good things about my company to others" were asked. Internal influence was measured with a 4-item scale intended to capture the extent to which a person takes individual initiative in communicating to the firm and co-workers about ways to improve service delivery by the organization, co-workers, and oneself, including "I make constructive suggestions for service improvement." Service delivery was measured with a 5-item scale that reflects the extent to which the employee serves customers in a conscientious, responsive, flexible, and courteous manner. Sample items include "I follow customer service guidelines with extreme care." and "I take time to understand customer needs on an individual basis" were asked.

\subsection{Sample Characteristics}

Questionnaires were distributed to 500 frontline employees across several banks. Of these, 322 usable questionnaires were returned, for a response rate of $64.4 \%$ (interviewer presence certainly aided this response rate). The employee sample is 49 percent male, with an average age of 35 years, ten-year tenure in the current position and $68.6 \%$ of the sample has a university degree.

\subsection{Measurement Model Analysis and Results}

To analyze the data, a structural equation model procedure using LISREL 8.5 was employed (Jöreskog and Sörbom 2001). Reliabilities 
〈Table 1〉 Frontline Employee Characteristics

\begin{tabular}{|c|c|c|}
\hline \multirow[b]{2}{*}{ Characteristics } & \multicolumn{2}{|c|}{ Customer contact employee } \\
\hline & Frequency & Percentage \\
\hline \multicolumn{3}{|l|}{ Age } \\
\hline 18 to 25 & 16 & 4.9 \\
\hline 26 to 39 & 202 & 62.2 \\
\hline 40 to 55 & 105 & 32.3 \\
\hline 56 or order & 2 & .6 \\
\hline \multicolumn{3}{|l|}{ Gender } \\
\hline Male & 168 & 49 \\
\hline Female & 174 & 50.7 \\
\hline \multicolumn{3}{|l|}{ Education } \\
\hline High school & 51 & 16 \\
\hline Collage & 28 & 8.8 \\
\hline University & 218 & 68.6 \\
\hline Graduated School & 6 & 1.9 \\
\hline Master Degree & 14 & 4.4 \\
\hline PhD Degree & 1 & .3 \\
\hline Mean number of year in present job & \multicolumn{2}{|c|}{$10.3 \mathrm{Yr}$} \\
\hline Range, number of year in present job & \multicolumn{2}{|c|}{0 to $34 \mathrm{Yr}$} \\
\hline Mean number of year of employment in customer contact related job & \multicolumn{2}{|c|}{$11.2 \mathrm{Yr}$} \\
\hline Range, number of year of employment in customer contact related job & \multicolumn{2}{|c|}{0 to $34 \mathrm{Yr}$} \\
\hline
\end{tabular}

of the individual measurement scales were assessed using Cronbach's coefficient $a$ and Fornell and Larker's (1981) composite reliability formula. Average variance extracted, composite reliability calculations, and items appear in Table 2and Table 3. The measurement model in this study consists of 28 reflective indicators and six correlated latent factors corresponding to the six constructs of the study depicted in Figure 1.

The first step in the analysis was to test the hypothesized measurement relationships and evaluate the reliability and discriminant validity of the constructs. To do this, a six-construct confirmatory factor analysis was estimated using the covariance matrix as input. Overall, the confirmatory factor model fit the data very well. The chi-square (df) was 570.944 (174), the comparative fit index (CFI) was .987, and the root mean squared error approximation (RMSEA) was .070 .

In addition, as shown in Table 2, the hypothesized factor loadings were all statistically significant at the .01 level, and the completely standardized factor loadings were all quite high and well above the recommended level of .50 .

As indicated in Table 2, the Cronbach alpha 
$\langle$ Table 2〉 Confirmatory Factor Analysis Results

\begin{tabular}{lcccc}
\hline \hline \multicolumn{1}{c}{ Construct } & items & Factor loading & $t$-value & Reliability \\
\hline Person organization fit (P-O fit) & 3 & $.605-.912$ & $22.459-23.622$ & .914 \\
Emotional exhaustion (EE) & 9 & $.614-.794$ & $22.859-25.942$ & .862 \\
Intrinsic motivation (IM) & 3 & $.746-.763$ & $24.096-24.536$ & .901 \\
Service Delivery (SD) & 5 & $.530-.746$ & $16.858-20.961$ & .894 \\
External representation & 4 & $.633-.659$ & $22.859-25.942$ & .926 \\
Internal Influence & 4 & $.672-.832$ & $21.096-24.388$ & .886 \\
\hline
\end{tabular}

reliability estimates were all well above Nunnally's (1978) recommended level of .70. Fornell and Larcker's (1981) index of the average amount of variance each latent factor accounted for in its indicators $(\operatorname{\rho vc}(n))$ was well above the recommended level of .50 for all of the constructs in Table 3. Evidence of discriminant validity is provided by the fact that all of the construct intercorrelations were significantly $(p<.05)$ less than 1.00: and the variance shared by any two constructs (i.e., the square of their intercorrelation) was always less than the $\operatorname{pvc}(n)$ 's for the constructs.

Harman's one factor test was conducted to minimize the threat of common method variance (CMV) accounting for the study's findings. First, the Harman's one-factor test was performed using confirmatory factor analysis. I linked all the measures of the six constructs to one single factor to perform the Harman's one factor test. Results of this one-factor model were $\mathrm{x} 2(189)=2506.894, \mathrm{p}<.001$, RMSEA $=$ .162, $\mathrm{GFI}=.662, \mathrm{AGFI}=.587, \mathrm{PNFI}=.839$ and $\mathrm{CFI}=.937$, which displayed a poor model fit. I compared this one-factor model with the six-factor model. The significant chi-square change $\left(\Delta \mathrm{x}^{2}(15)=1,935.95, \mathrm{p}<.001\right)$ indicated that the respondents of this study could dis-

〈Table 3〉 Measure Correlations, Composite Reliability and Average Variance Extracted

\begin{tabular}{|c|c|c|c|c|c|c|c|c|}
\hline & POF & $\mathrm{IM}$ & $\mathrm{EE}$ & SD & ER & II & $\mathrm{CR}$ & AVE \\
\hline $\mathrm{POF}$ & & & & & & & 0.914 & 0.781 \\
\hline $\mathrm{IM}$ & $0.402^{* *}$ & & & & & & 0.902 & 0.754 \\
\hline $\mathrm{EE}$ & $-0.185^{* *}$ & $-0.271^{* *}$ & & & & & 0.908 & 0.665 \\
\hline $\mathrm{SD}$ & $0.527^{* *}$ & $0.450^{* *}$ & $-0.124^{* *}$ & & & & 0.884 & 0.658 \\
\hline $\mathrm{ER}$ & $0.541^{* *}$ & $0.376^{* *}$ & $-0.145^{* *}$ & $0.549^{* *}$ & & & 0.930 & 0.771 \\
\hline II & $0.490^{* *}$ & $0.408^{* *}$ & $-0.270^{* *}$ & $0.428^{* *}$ & $0.446^{* *}$ & & 0.858 & 0.752 \\
\hline
\end{tabular}

Note: Person organization fit (POF). Intrinsic motivation (IM), Emotional exhaustion (EE), Service delivery (SD), External representation (ER), Internal Influence (II).

** significant at $<0.01$. 
tinguish the six constructs well.

\subsection{Results and Analysis}

I tested the hypotheses proposed herein using structural equation modeling with LISREL 8.5 (Jöreskog and Sörbom 2001). The overall fit of this model was good. The Chi-square (df) was 261.710 (68), CFI was .986, and NFI was .981 and GFI was .923. The structural estimates of this model are shown in Table 4. As shown, the analyses provide support for all nine of the hypothesized relationships (with hypotheses 4 and 5 having three components, respectively).

\subsection{Mediating Effects}

As there was more than one mediating effect in the structural model, in order to separate the indirect effects and test the significance of each of the mediating effects and test the significance of each of the mediating effects, phantom variables and bias-corrected bootstrap were used. The researcher requested AMOS to generate 1,000 bootstrap samples and selected biascorrected bootstrap method with 95 percent of confidence intervals (Mallinickrodt et al. 2006). 〈Table 5〉 shows the mediating effects of intrinsic motivation and emotional exhaustion be-

〈Table 4〉 Result of Hypothesized Relationships

\begin{tabular}{|c|c|c|c|c|c|}
\hline Hypothesized relationships & $\begin{array}{c}\text { Unstandardized } \\
\text { estimates }\end{array}$ & $\begin{array}{l}\text { Std } \\
\text { error }\end{array}$ & $\begin{array}{c}\text { Standardized } \\
\text { estimates }\end{array}$ & $t$-value & Conclusion \\
\hline $\begin{array}{l}\text { Person organization fit } \rightarrow \\
\text { Emotional exhaustion }\end{array}$ & -0.898 & 0.059 & -0.831 & -15.313 & H1 supported \\
\hline $\begin{array}{l}\text { Person organization fit } \rightarrow \\
\text { Intrinsic motivation }\end{array}$ & 0.264 & 0.086 & 0.273 & 3.062 & H2 supported \\
\hline $\begin{array}{l}\text { Emotional exhaustion } \rightarrow \\
\text { Intrinsic motivation }\end{array}$ & -0.439 & 0.083 & -0.491 & -5.302 & H3 supported \\
\hline $\begin{array}{l}\text { Emotional exhaustion } \rightarrow \\
\text { Service Delivery }\end{array}$ & -0.514 & 0.059 & -0.543 & -8.791 & H4 supported \\
\hline $\begin{array}{l}\text { Emotional exhaustion } \rightarrow \\
\text { External representation }\end{array}$ & -0.650 & 0.057 & -0.681 & -11.488 & H5 supported \\
\hline $\begin{array}{l}\text { Emotional exhaustion } \rightarrow \\
\text { Internal influence }\end{array}$ & -0.419 & 0.054 & -0.500 & -7.822 & H6 supported \\
\hline $\begin{array}{l}\text { Intrinsic motivation } \rightarrow \\
\text { Service Delivery }\end{array}$ & 0.350 & 0.062 & 0.330 & 5.618 & H7 supported \\
\hline $\begin{array}{l}\text { Intrinsic motivation } \rightarrow \\
\text { External representation }\end{array}$ & 0.244 & 0.056 & 0.228 & 4.330 & H8 supported \\
\hline $\begin{array}{l}\text { Intrinsic motivation } \rightarrow \\
\text { Internal influence }\end{array}$ & 0.332 & 0.057 & 0.353 & 5.804 & H9 supported \\
\hline
\end{tabular}


〈Table 5〉 Results of Mediating Effects Test

\begin{tabular}{cclcc}
\hline \hline \multicolumn{1}{c}{ Mediator } & IV & \multicolumn{1}{c}{ DV } & Effect & Significance \\
\hline Intrinsic Motivation & P-O fit & Service Delivery & 0.451 & 0.001 \\
& & External Representation & 0.565 & 0.003 \\
& & Internal Influence & 0.408 & 0.007 \\
Emotional Exhaustion & \multirow{2}{*}{ P-O fit } & Service Delivery & 0.08 & 0.045 \\
& & External Representation & 0.06 & 0.028 \\
& & Internal Influence & 0.09 & 0.005 \\
\hline
\end{tabular}

tween $\mathrm{P}-\mathrm{O}$ fit and employees' boundary spanning behavior (service delivery, external representation, and internal influence).

From the bias-corrected bootstrap test result, it was confirmed that intrinsic motivation significantly and partially mediated the influence of $\mathrm{P}-\mathrm{O}$ fit on service delivery, external representation, and internal influence. Emotional exhaustion was found to play a significant, but partial mediating role on the $\mathrm{P}-\mathrm{O}$ fit and employees' boundary spanning behavior service delivery, external representation, and internal influence.

\section{Discussion}

\subsection{General Discussion of Results}

This study extends prior research of Bettencourt and Brown (2003) and Bettencourt et al. (2001) by linking the relationship between $\mathrm{P}-\mathrm{O}$ fit and BSB with two psychological mechanisms (i.e., emotional exhaustion and intrinsic motivation). With regard to the linkage of employee's psychological responses, this research finds that an employee's perceived fit with his/her organization enhances intrinsic motivation and reduces emotional exhaustion. These mechanisms, in turn, increase the employee BSB. These results support the notion that person-organization fit should be one of the factors affecting motivation, affect and attachment (O’Reilly et al. 1991), and extends such an understanding to a purely service-based environment among customer contact employees. Such an understanding demonstrates the significance on properly aligned employment in a service setting.

In addition, past research has generally demonstrated the direct relationship between $\mathrm{P}-\mathrm{O}$ fit and employee pro-social behavior, although there has been scant research investigating the underlying mechanisms between frontline employee $\mathrm{P}-\mathrm{O}$ Fit and $\mathrm{BSB}$. In line with this, Podsakoff et al. (2000) suggest that future research should start to further map the relationships among the antecedents of employee pro- 
social behavior. To answer Podsakoff et al. (2000)'s recommendation, the present study not only investigates the linking mechanisms between customer contact employee $\mathrm{P}-\mathrm{O}$ fit and $\mathrm{BSB}$, but also clarifies the relationships among these antecedent variables of BSB.

The literature investigating antecedents to $\mathrm{OCB}$ (BSB) is further expanded by the mediating model presented in this study. Research relating to intrinsic motivation to $\mathrm{OCB}$ is surprisingly rare. The results of this study demonstrate that intrinsic motivation is significantly related to the three types of BSB. According to Bettencourt and Brown (2003), for the majority of frontline employees, service delivery behaviors are likely to be relatively more role prescribed due to their frequent specification in job descriptions, training materials and performance evaluation forms. However, external representation and internal influence behaviors are likely to be relatively more discretionary (Bettencourt and Brown 2003). Thus, inference indicates that intrinsic motivation is more related to frontline employee in-role behavior.

Further, the current results are consistent with the job demand-resource (JD-R) model. Thus, the findings suggest that instead of directly affecting boundary spanning behaviors, job resource (person-organization fit) indirectly affect boundary spanning behaviors via increased levels of intrinsic motivation. On a more general level, this supports Hackman and Oldham's (1976) Job Characteristics Theory that assumes that critical psychological states (i.e. meaningfulness, responsibility, and knowledge of the results) mediate job characteristics (i.e. resources such as variety, task identity, task significance, autonomy and feedback) and outcomes (i.e. motivated proactive behavior).

Next, when job resources increase, emotional exhaustion tends to decrease as well (Hypothesis 2). According to Schaufeli and Bakker (2004), job resources may play an extrinsic motivational role because they are instrumental in achieving work goals. Because, according to the EffortRecovery model (Meijman and Mulder, 1998). work environments that offer many resources foster the willingness to dedicate one's efforts and abilities to the work task. Thus, the results confirm the role of $\mathrm{P}-\mathrm{O}$ fit in predicting service employee emotional exhaustion. A employee who feels that the prevailing norms and values of the company are compatible with her or his own values may experience a particular type of contextual consonance. A contextual consonance may result in a feeling of belonging. Thus I can expect that this type of congruence clearly increase employee's trust, commitment and job satisfaction and diminish the negative stress. emotional exhaustion.

Next, the results also indicate that the effects of emotional exhaustion on employee external representation and internal influence are stronger than the link between emotional exhaustion and service delivery. This suggests that emotional exhaustion is more related to employee 
extra-role behaviors, as based on the suggestions of Bettencourt and Brown (2003).

In the previous section, I found that emotional exhaustion has bigger effects on frontline employee boundary spanning behavior. Thus, even if a service manager cannot control an employee's P-O fit through selective hiring, the manager should be able to exert some level of control through attempts to reduce an employee's emotional exhaustion rather than increasing intrinsic motivation. It appears that a reduction in emotional exhaustion has positive consequences related to BSB that go well beyond the effects of increasing motivation.

Although the results of this study do demonstrate that intrinsic motivation should not be overlooked, as it mediates the relationship between emotional exhaustion and employee BSB. This finding has implications for the JD-R (job demands and resources) model. In JD-R model, emotional exhaustion is a result of job demand, which may decrease employee performance. The present research adds to the literature by showing that motivational factors buffer the effect of an employee's negative emotional reaction on displays of BSB.

\subsection{Managerial Implication}

This study shows that P-O fit can make a difference to frontline employee intrinsic motivation and emotional exhaustion. As such, in situations where employee values do not fit their organization's values, frontline employees show low intrinsic motivation and high emotional exhaustion. These results suggest that organizations have to do their best to manage $\mathrm{P}-\mathrm{O}$ fit, be it through employee screening or training and workshops to try and align organization and employee values and objectives. For example, from a practical point-of-view, one could argue that employees apparently are very sensitive to the general perceptions of their work group. Social information processing research has convincingly shown that employees' perceptions can be influenced through the communication and behaviors of their supervisors. Since supervisors determine organizational values and norms (Greenberg 1990), leadership plays an important role in influencing employee perceptions (Aquino et al. 1999). If managers of organizations are positively evaluated by the employees, it will be easier for them to, "give things of value to followers (employees), such as sense of direction, values, and recognition, and receive other things in return such as esteem and responsiveness" (Hollander 1987, p. 16). Consequently, organizational leaders are not only able to manage employee experiences, but also their fit with the organization (Van Vienan et al. 2007).

In this research I explain the importance of psychological variables for predicting employee behaviors. Compared to intrinsic motivation, emotional exhaustion showed more explanatory power in predicting frontline employee boun- 
dary spanning behaviors through the combination of direct and indirect effects. Thus, even if a manager cannot control employee $\mathrm{P}-\mathrm{O}$ fit, this research suggests, that a focus on reducing emotional exhaustion rather than increasing intrinsic motivation seems optimal.

These results suggest, the importance of intrinsic motivation is not discounted. Indeed. this research also supports the idea that motivation has a direct association with a frontline employee's boundary spanning behavior. Even in situations where emotional exhaustion cannot be reduced, organizations may still influence frontline behaviors through motivation. Motivation theorists have suggested a multiplicity of mechanisms for increasing motivation, including increasing equity perceptions (Adams 1963), increasing linkages among ability perceptions, reward attainability, and the value of the rewards (Vroom 1964) or appropriate job design (Hackman and Oldham 1976), among others.

\subsection{Limitations and Future Research}

This study suffers from common limitations of cross-sectional field research, including the inability to make causal inferences. First, although the study investigated a structural model of relationships among variables, one can only conclude that the model is a feasible explanation of the observed relationships in the data. The direction of paths in the model relies on prior research.

Second, the study investigated a theoretical model using various banks in South Korea, but the generalizability of the findings beyond this context relies on additional research. Further, recent research by Donavan et al. (2004) suggests that it would also be worthwhile to consider individual customer orientation as an antecedent of frontline employee boundary spanning behavior. Their research also suggests that it would be worthwhile to investigate the role of job satisfaction and organizational commitment as mediators of any effect of customer orientation as a predictor of frontline boundary spanning behavior. In short, many other variables may be involved in this process. The current study simply serves as a foundation from which to build.

Third, the critical role of $\mathrm{P}-\mathrm{O}$ fit on employee's BSB was examined but did not incorporate the impact of other job resources to understand the process of employee's psychological aspects more thoroughly. For future research, specific types of job resources which are unique to service employees could be added, such as customer orientation, perceived fit with customer ( $\mathrm{P}-\mathrm{C}$ fit) or customer support, to better understand the effect of job resources on frontline employees' motivation and/or burnout.

〈Received February 27. 2013〉

〈Revised April 2. 2013〉

〈Accepted April 9. 2013〉 


\section{References}

Adams, Stacy J. (1963), "Towards an Understanding of Inequity," Journal of Abnormal and Social Psychology, 67 (November), 422-36.

Aquino, Karl, Margaret U. Lewis, and Murray Bradfield (1999), "Justice Constructs, $\mathrm{Ne}^{-}$ gative Affectivity, and Employee Deviance: A Proposed Model and Empirical Test," Journal of Organizational Behavior, 20 (December), 1073-91.

Babakus, David W.. Cravens M. Johnston, and William C. Moncrief (1999), "The Role of Emotional Exhaustion in Sales Force Attitude and Behavior Relationships," Journal of the Academy of Marketing Science, 27 (January), 58-70.

Bakker, Arnold B. and Evangelia Demerouti (2007), "The Job Demands - Resources Model: State of the Art," Journal of Managerial Psychology, 22 (3), 309-328. Taris, W. Toon, Wilmar B. Schaufeli, and Paul J. G. Schreurs (2003), "A Multi-Group Analysis of the Job Demands - Resources Model in Four Home Care Organizations," International Journal of Stress Management, 10 (February), 16-38. and Verbeke Willem (2004),

"Using the Job Demands - Resources Model to Predict Burnout and Performance." Human Resource Management, 43 (1), 83-
104.

Bettencourt, Lance A., Kevin P. Gwinner, and Matthew L. Meuter (2001), “A Comparison of Attitude, Personality, and Knowledge Predictors of Service-Oriented Organizational Citizenship Behaviors," Journal of Applied Psychology, 86 (February), 29-41. and Stephen W. Brown (1997),

"Contact employees: Relationships among Workplace Fairness, Job Satisfaction and Pro-social Service Behaviors," Journal of Retailing, 73 (1), 39-61. and (2003), "Role

Stressors and Customer-Oriented BoundarySpanning Behaviors in Service Organizations," Journal of the Academy of Marketing Science, 31 (October), 394-408. and Scott B. MacKenzie (2005), "Customer-Oriented Boundary-Spanning Behaviors: Test of a Social Exchange Model of Antecedents." Journal of Retailing, 81 (2), 141-57.

Boles, James S., Mark W. Johnston, and Joseph F. Hair, Jr. (1997), "Role Stress, Work-Family Conflict and Emotional Exhaustion: Interrelationships and Effects on Some WorkRelated Consequences," Journal of Personal Selling and Sales Management, 17 (1), 1728.

Borman, Walter C. and Stephan J. Motowidlo (1993), "Expanding the Criterion Domain to Include Elements of Contextual Performance," in Personnel selection in organiza- 
tions, Neal Schmitt and Walter C. Borman eds. San Francisco: Jossey-Bass, 71-98.

Bowen, David E., Stephen W. Gilliland, and Robert Folger (1999), "How Being Fair with Employees Spills Over to Customers," Organizational Dynamics, 27 (3), 7-23.

Bright, Leonard (2007), "Does Person-Organization Fit Mediate the Relationship Between Public Service Motivation and the Job Performance of Public Employee?," Review of Public Personnel Administration, 27 (4), 361-379.

Brislin, Richard W. (1970), "Back-Translation for Cross-Cultural Research," Journal of Cross-Cultural Research, 1 (September), 185-216

Brotheridge, Céleste M., and Alicia A. Grandey (2002), "Emotional Labor and Burnout: Comparing Two Perspectives of People Work," Journal of Vocational Behavior, 60 (1), 17-39.

Cable, Daniel M. and Timothy A. Judge (1996), "Person-Organization Fit, Job Choice Decisions, and Organizational Entry," Organizational Behavior and Human Decision Processes, 67 (September), 294-311.

Cordes, Cynthia L. and Thomas W. Dougherty (1993), "A Review and an Integration of Research on Job Burnout," The Academy of Management Review, 18 (4), 621-656.

Cropanzano, Russel, Deborah, E. Rupp, and Zinta, S. Byrne (2003), "The Relationship of Emotional Exhaustion to Work Atti- tudes, Job Performance and Organizational Citizenship Behaviors," Journal of Applied Psychology, 88 (February), 160-69. Deborah E. Rupp, Carolyn J. Mphler and Marshall Schminke (2001), Three Roads to Organizational Justice. In J. Ferris (Ed.), Research in Personnel and Human Resources Management (Vol. 20, pp. 1 -113). Greenwich, CT: JAI Press. Demerouti, Evangelia, Arnold B. Bakker, Nachreiner, F., and Wilmar B. Schaufeli (2001). "The Job Demands - Resources Model of Burnout," Journal of Applied Psychology, 86 (June), 499-512.

Donavan, Todd B., Tom J. Brown, and John C. Mowen (2004), "Internal Benefit of Serviceworker Customer Orientation: Job Satisfaction. Commitment and Organizational Citizenship Behavior," Journal of Marketing. 68 (January), 128-46.

Fornell, Claes and David F. Larker (1981), "Evaluating Structural Equation Models with Unobservable Variables and Measurement Error," Journal of Marketing Research. 18 (February), 39-50.

Greenberg, Jerald (1990), "Employee Theft as a Reaction to Underpayment Inequity: The Hidden Cost of Pay Cuts," Journal of Applied Psychology, 75 (October), 561-68.

Gwinner, Kevin P., Mary Jo Bitner, Stephen W. Brown, and Ajith Kumar (2005), "Service Customization through Employee Adaptiveness," Journal of Service Research, 8 
(November), 131-48.

Hackman, Richard J., and Greg R. Oldham (1976), “Motivation through the Design of Work: Test of a theory," Organizational Behavior and Human Decision Process, 16 (2), 250-79. and (1980), Work

Redesign, Reading, MA: Addison-Wesley. Halbesleben, Jonathon R. B., and Matthew, W. Bolwer (2007), “Emotional Exhaustion and Job Performance: The Mediating Role of Motivation," Journal of Applied Psychology, 92 (January), 93-106.

Hendrix, William H., Tina Robbins, Janis

Miller, and Timothy P. Summers (1998), "Effects of Procedural and Distributive Justice on Factors Predictive of Turnover," Journal of Social Behavior and Personality, 13 (4), 1-21.

Hennig-Thurau, Thorsten, Markus Groth, Michael Paul, and Dwayne D. Gremler (2006), “Are All Smiles Created Equal? How Emotional Contagion and Emotional Labor Affect Service Relationship," Journal of Marketing. 70 (July), 58-73.

Hobfoll, Stevan E. (1989), "Conservation of Resources: A New Attempt at Conceptualizing Stress," American Psychologist, 44 (March), 513-24. (2002), "Social and Psychological Resources and Adaptation," Review of General Psychology, 6 (December), 307324.
Hochschild, Arlie R. (1983), The Managed Heart: Commercialization of Human Feeling. Berkeley, CA: University of California Press. Hollander, Edwin P. (1987), College and University Leadership from a Social Psychological Perspective: A Transactional View, New York: Columbia University. Jaramillo, Fernando, Jay P. Mulki, and Paul Solomon (2006), "The Role of Ethical Climate on Salesperson's Role Stress, Job Attitudes, turnover Intention, and Job Performance," Journal of Personal Selling and Sales Management, 26 (3), 271 - 282.

Jöreskog, Karl G., and Dag Sörbom (2001), LISREL 8.51. Lincolnwood, IL: Scientific Software International.

Karatepe, Osman M., and Mehmet Tekinkus (2006), "The Effects of Work-Family Conflict, Emotional Exhaustion, and Intrinsic Motivation on Job Outcomes of Front-Line Employees," International Journal of Bank Marketing, 24 (3), 173-93.

Keaveney, Susan M., and James E. Nelson (1993). "Coping with Organizational Role Stress: Intrinsic Motivational Orientation, Perceived Role Benefits, and Psychological Withdrawal," Journal of the Academy of Marketing Science, 21 (March), 113-24.

Leithwood, Kenneth A., Teresa Menzies, Doris Jantzi, and Jennifer Leithwood (1999), Teacher Burnout: A Critical Challenge for Leaders of Restructuring Schools. In A. M. Huberman (Ed.), Understanding and Pre- 
venting Teacher Burnout: A Source book of International Research and Practice (pp. 85 -114). New York: Cambridge University Press.

Luria, G., Iddo Gal, and Dana Yagil (2009), 'Employees' Willingness to Report Service Complaints," Journal of Service Research, 12 (November), 156-74.

Mallinckrodt, Brent, W. Todd Abraham, Meifen Wei, and Dniel W. Russell (2006), "Advances in Testing the Statistical Significance of Mediation Effects," Journal of Counselling Psychology, 53 (3), 372-78.

Maslach, Christina (1982), Burnout: The Cost of Caring, New York: Prentice-Hall, and Jackson E. Susan (1981), "The Measurement of Experienced Burnout," Journal of Occupational Behavior. 2 (April), 99-113.

Meijman, Theo F. and Gbertusijs Mulder (1998), Psychological Aspects of Workload. In P. J. D. Drenth, and H. Thierry (Eds.), Handbook of Work and Organizational Psychology, Vol. 2:Work Psychology (pp. 5 -33). Hove: Psychology Press.

Morris, Andrew J. and Deniel C. Feldman (1996), "The Dimensions, Antecedents, and Consequences of Emotional Labor," Academy of Management Review, 21 (October), 9861010.

Netemeyer, Richard G., James S. Boles, Daryl O. McKee, and Robert McMurrian (1997), "An Investigation into the Antecedents of
Organizational Citizenship Behaviors in a Personal Selling Context," Journal of Marketing, 61 (May), 85-98.

Nunnally, Jun C. (1978), Psychometric Theory, 2ed. New York: McGraw-Hill.

Oldham, Greg R., and Richard J. Hackman (1981), "Relationships between Organizational Structure and Employee Reactions: Comparing Alternative Frameworks," $A d-$ ministrative Science Quarterly, 26 (1), 6683.

O'Reilly, Charles A., and Chatman Jennifer (1986), "Organizational Commitment and Psychological Attachment: The Effects of Compliance, Identification, and Internalization on Pro-social Behavior," Journal of Applied Psychology, 71 (August), 492-99. and David F. Caldwell (1991), "People and Organizational Culture: A Profile Comparison Approach to Assessing Person-Organization Fit," Academy of Management Journal, 34 (3). 487-516.

Park, Jeong Eun, Besty, B. Holloway, and Sungho, Lee (2013), "The Benefit of Sales Force Automation Explored: An Empirical Examination of SFA Usage on Relationship Quality and Performance," Asia Marketing Journal, 14 (4), 143-166.

Podsakoff, Philip M., and Scott B. MacKenzie (1997), "The Impact of Organizational Citizenship Behavior on Organizational Performance: A Review and Suggestions for 
Future Research," Human Performance, 10 (2), 133-151.

Podsakoff, Philip M., Scott B. MacKenzie, Julie B. Paine and Daniel G. Bachrach (2000), "Organizational Citizenship Behavior: A Critical Review of Theoretical and Empirical Literature and Suggestions for $\mathrm{Fu}^{-}$ ture Research, Journal of Management. 26 (June), 513-563.

Posner, Barry Z. (1992), "Person-Organization Values Congruence: No Support for Individual Differences as a Moderating Influence," Human Relations, 45 (April), 35161.

Richard, Oliver L. and Erin Anderson (1994), "An Empirical Test of the Consequences of Behavior- and Outcome-Based Sales Control Systems," Journal of Marketing, 58 (July), 53-67.

Ryan, Richard M. and Edward L. Deci (2000). "Self-Determination Theory and the Facilitation of Intrinsic Motivation, Social Development, and Well-Being," American Psychologist, 55 (January), 68-78.

Schaufeli, Wilmar B. and Arnold B. Bakker (2004), "Job Demands, Job Resources, and Their Relationship with Burnout and Engagement," Journal of Organizational Behavior, 25 (May), 293 - 315. and Willem Van Rhenen (2009), "How Changes in Job Demands and Resources Predict Burnout, Work Engagement, and Sickness Absenteeism,"
Journal of Organizational Behavior, 30 (August), 893 - 917.

Schneider, Benjamin, Harold W. Goldstein, and Smith D. Brent (1995), "The ASA Framework: An Update," Personnel Psychology, 48 (December), 747-73.

Singh, Romila and Jeffrey H. Greenhaus (2004), "The Relation between Career DecisionMaking Strategies and Person-Job Fit: A study of Job Changers," Journal of Vocational Behavior, 64 (February), 198-21.

Spreitzer, Gretchen M. (1995), "Individual Empowerment in the Workplace: Dimensions, Measurement, and Validation," Academy of Management Journal, 38 (5), 1442-65.

Staw, B. M. (1977), "Motivation in organizations: Toward Synthesis and Redirection" in New directions in Organizational Behavior, B. M. Staw and G. Salancik, eds. Chicago: St. Clair Press, 55-95.

Van Vianen Annelies, E. M., Irene E. De Pater and Floor Van Dijk (2007), "Work Value Fit and Turnover Intention: Same-Source or Different-Source Fit," Journal of $\mathrm{Ma}^{-}$ nagerial Psychology, 22 (2), 188-202.

Vroom, Victor H. (1964), Work and Motivation, New York: Wiley.

Wayne, Sandy J., Lynn M. Shore, and Robert C. Liden (1997), "Perceived Organizational Support and Leader-Member Exchange: A Social Exchange Perspective," Academy of Management Journal, 40 (1), 82-111. Wharton, Amy S. (1993), "The Affective Con- 
sequences of Service Work," Work and Occupations, 20 (2), 205 - 232.

Wright, Thomas A, and Douglas G. Bonett (1997), "The Contribution of Burnout to Work Performance," Journal of Organizational Behavior, 18 (September), 491-99. and Russell Cropanzano (1998). "Emotional Exhaustion as a Predictor of Job Performance and Voluntary Turnover," Journal of Applied Psychology, 83 (June), 486-93.
Xie, Jia Lin, and Gary Johns (1995), "Job Scope and Stress: Can Job Scope be Too High?" Academy of Management Journal, 38 (5), 1288-1309.

Zoghbi, Pablo Manrique de Lara and Tomás F. and Espino Rodríguez (2007), "Organizational Anomie as Moderator of the Relationship between an Unfavorable Attitudinal Environment and Citizenship Behavior (OCB): An Empirical Study among University Administration and Services Personnel," Personnel Review, 36 (6), 843-66. 


\section{〈Appendix〉}

\section{Measures of Variables}

\begin{tabular}{|c|c|}
\hline Construct and Source & Scales \\
\hline $\begin{array}{l}\text { Person-Organization Fit } \\
\text { (Netemeyer et al. 1987) }\end{array}$ & $\begin{array}{l}\text { I feel that my personal values are a good fit with my company. } \\
\text { My company has the same value as I do with regard to concern for others. } \\
\text { My company has the same values as I do with regard to honesty. } \\
\text { My company has the same values as I do with regard to fairness. }\end{array}$ \\
\hline $\begin{array}{l}\text { Emotional Exhaustion } \\
\text { (Maslach and Jackson } \\
\text { 1981) }\end{array}$ & $\begin{array}{l}\text { I feel emotionally drained from my work. } \\
\text { I feel fatigued when I get up in the morning and have to face another day on } \\
\text { the job. } \\
\text { I feel burned out from my work. } \\
\text { I feel frustrated by my job. } \\
\text { I feel used up at the end of the workday. } \\
\text { I feel like Im at the end of my rope. } \\
\text { I feel I am working too hard on my job. } \\
\text { Working with people all day is really a strain for me. } \\
\text { Working directly with people directly puts too much stress on me. }\end{array}$ \\
\hline $\begin{array}{l}\text { Intrinsic Motivation } \\
\text { (Richard and Anderson } \\
\text { 1994) }\end{array}$ & $\begin{array}{l}\text { When I perform well, I know it's because of my own desire to achieve. } \\
\text { I don't need a reason to provide good service: I do this for the challenge of it. } \\
\text { Becoming successful in my job is something that I want to do for me. } \\
\text { If I were independently wealthy, I would still work at my job for the } \\
\text { challenge of it. } \\
\text { I wish I didn't have to retire someday so I could always continue working for } \\
\text { the pleasure of it. } \\
\text { I work because I cherish the feeling of performing a useful service. }\end{array}$ \\
\hline $\begin{array}{l}\text { Service Delivery } \\
\text { (Bettencourt et al. 2005) }\end{array}$ & $\begin{array}{l}\text { I follow customer service guidelines with extreme care. } \\
\text { I follow up in a timely manner to customer requests and problems. } \\
\text { Regardless of circumstances, I am exceptionally courteous and respectful to } \\
\text { customers. } \\
\text { I follow through in a conscientious manner on promises to customers. } \\
\text { I take time to understand customer needs on an individual basis. }\end{array}$ \\
\hline $\begin{array}{l}\text { External Influence } \\
\text { (Bettencourt et al. 2005) }\end{array}$ & $\begin{array}{l}\text { I tell outsiders this is a great place to work. } \\
\text { I generate favorable goodwill for my company. } \\
\text { I say good things about my company to others. } \\
\text { I encourage friends and family to use my company's products and services. }\end{array}$ \\
\hline $\begin{array}{l}\text { Internal Influence } \\
\text { (Bettencourt et al. 2005) }\end{array}$ & $\begin{array}{l}\text { I make constructive suggestions for service improvement. } \\
\text { I contribute many ideas for customer promotions and communications. } \\
\text { I share creative solutions to customer problems with other team members. } \\
\text { I encourage co-workers to contribute ideas and suggestions for service } \\
\text { improvement. }\end{array}$ \\
\hline
\end{tabular}

